\title{
Chapter 16 \\ Belief Changes in the Transition \\ from University Studies to School \\ Practice
}

\author{
Ralf Erens and Andreas Eichler
}

\begin{abstract}
Teachers' intended instructional design of lessons are represented by their belief systems as a part of mathematics-related affect. This chapter focuses on 20 prospective secondary teachers' beliefs towards their teaching of calculus at uppersecondary level. The theoretical framework in relation to the international discussion on beliefs and affect and methodological considerations referring to a qualitative design will be outlined. Afterwards the focus lies on studying these teachers' beliefs with a particular concern for how these beliefs might change depending on the stage of their professional development. Results from a qualitative study of preservice teachers and teacher trainees will be discussed centred on whether and how changes in their belief systems occur. Our results show that the teachers' central beliefs remain stable whereas subordinated and peripheral beliefs slightly change.
\end{abstract}

Keywords Teacher beliefs $\cdot$ Calculus $\cdot$ Professional development $\cdot$ Belief change

\subsection{Introduction}

Teachers are challenged to consistently change or to modify their beliefs beyond a status quo achieved after university studies (Clarke \& Hollingsworth, 2002). This individual and life-long learning aims to achieve the overarching goal for mathematics instruction, i.e. to seek a teaching style that facilitates the best possible students' learning.

Teachers' beliefs and goals as a target of the mentioned life-long learning are understood to impact on both the teachers' actual teaching of mathematics (e.g. Eichler \& Erens, 2015) and also the teachers' professional development (e.g. Philipp, 2007). For this reason, it is an important challenge for research in mathematics edu-

R. Erens $(\varangle)$

University of Education Freiburg, Kunzenweg 21, 79117 Freiburg, Germany

e-mail: ralf.erens@ph-freiburg.de

A. Eichler

University of Kassel, Heinrich-Plett-Straße 40, 34132 Kassel, Germany

e-mail: eichler@mathematik.uni-kassel.de 
cation to investigate the status quo and the development of mathematics teachers' beliefs. Speer (2005, p. 365) expressed the importance of teachers' beliefs as follows: "Beliefs appear to be, in essence, factors shaping teachers' decisions about what knowledge is relevant, what teaching routines are appropriate, what goals should be accomplished, and what the important features are of the social context of the classroom." However, Schraw and Sinatra (2004, p. 100) stated to the research concerning teachers' beliefs development that "[t]here has been little research on teachers' personal epistemologies, how these beliefs develop and are affected by teacher education". A similar statement is given by Levin (2015) ten years later. For this reason, one main aim of this chapter is to make a contribution to the research concerning the development of prospective mathematics teachers' beliefs.

Existing research indicates several phases in which a development and also a change of teachers' beliefs took place (e.g. Oliveira \& Hannula, 2008). First of all, a highly relevant phase of the belief development is located before teachers become teachers, i.e. in the teachers' own school-time (e.g. Kaasila, Hannula, Laine, \& Pehkonen, 2006; Richardson, 2003). A further main phase of the professional socialisation of teachers is-after the crucial transition from school to university (e.g. Gueudet, Bosch, Disessa, Kwon, \& Verschaffel, 2016)_ given by these teachers' university studies (e.g. Fives \& Buehl, 2012). In this phase, teacher educators try to ensure that prospective teachers' beliefs are developed according to educational goals. For example, Bernack-Schüler, Leuders, and Holzäpfel (2015) reported a case that shows the failed attempt of teacher educators to change the beliefs of students. Research has identified a further crucial phase of belief development when teachers acquire their first experiences in the classroom (Huberman, 1989; Oliveira \& Hannula, 2008). This phase could consist of a so-called "shock due to practice" (Dann, Müller-Fohrbrodt, $\&$ Cloetta, 1981) that describes a phase when teachers' beliefs are challenged by the teachers' first practical experiences. Again, there are few findings concerning this phase in either education research (Levin, 2015) or in mathematics education research (e.g. Oliveira \& Hannula, 2008). The research of Dann et al. (1981) made the prediction that teachers tend to neglect reform-oriented or student-centred teaching styles, when they teach on their own the first time, but, however, return to teaching orientations that they learned in university studies (cf. also Oliveira \& Hannula, 2008). Of course, mathematics teachers might change their beliefs also in their phase as qualified teachers and teacher trainers in professional development courses aiming to develop teachers' beliefs (e.g. Liljedahl, 2010). However, in this paper, we focus on the phase of mathematics teachers' development between the end of their university studies and their start as qualified teachers, i.e. a phase that lasts 18 months in Germany (cf. Eichler \& Erens, 2014).

This report addresses one main topic of our research programme, i.e. to investigate the development of mathematics teachers' beliefs. In this research programme, we restrict our focus to calculus. The rationale for this focus is given by some evidence that teachers' beliefs differ concerning different mathematical topics (Eichler \& Erens, 2015; Franke, Kazemi, \& Battey, 2007). For example, a teacher's belief towards modelling as a central part of mathematics teaching may considerably vary if the teacher is thinking about geometry, statistics or calculus (Eichler \& Erens, 
2015). Accordingly it is reasonable to also restrict the focus on a specific mathematical discipline when regarding the development of teachers' beliefs. For example, if a teacher mentions different beliefs about mathematics in general at different times, it is not possible to reconstruct if the teacher changed his beliefs or if the teacher has different mathematical disciplines in mind. To avoid a bias based on teachers' different beliefs towards different mathematical disciplines is the main reason to focus on a specific mathematical discipline for this paper, i.e. calculus. Since there is a lack of research referring to teachers' beliefs towards calculus (cf. Bressoud, Ghedamsi, Martinez-Luaces, \& Törner, 2016; Gutiérrez, Leder, \& Boero, 2016), we focus in depth on the specificity of calculus teachers' beliefs in our research program. However, due to the focus for this paper, i.e. the development of teachers' beliefs, we discuss the specificity of beliefs towards calculus only secondarily.

To conclude, the present chapter aims to focus on the development of secondary mathematics teacher beliefs towards calculus as the central part of the mathematics syllabus of upper secondary education in Germany. For this, we outline our theoretical framework consisting of a brief summary of the construct of beliefs and specific trends in teaching calculus. We further refer to the method of our research. A main part of this chapter is to explicate our findings concerning the following two research questions:

- To what extent do distinguishable features in the structure of prospective secondary teachers' beliefs towards teaching calculus change in the transition between the end of their university studies and their start as qualified teachers?

- What are the reasons for potential beliefs changes in the course of professional education as a teacher?

We conclude this chapter with a discussion of our research findings and brief comments concerning possible issues for future research.

\subsection{Theoretical Framework}

\subsubsection{Teacher Beliefs}

Beliefs could be understood as part of mathematics-related affect (Hannula, 2012). In this framework beliefs consist of cognitive, motivational and affective aspects (Hannula, Op 't Eynde, Schlöglmann, \& Wedege, 2007; Fig. 16.1). According to this model, we regard teachers' beliefs and teachers' goals, and, thus, we investigate the intersection of cognitive and motivational aspects of teachers' mathematics-related affect.

Using the definition of Philipp (2007) and Pajares (1992) a teacher's beliefs could be understood as his or her propositions about a certain topic that are individually thought to be true. For example, a teacher could hold the following belief (propo- 


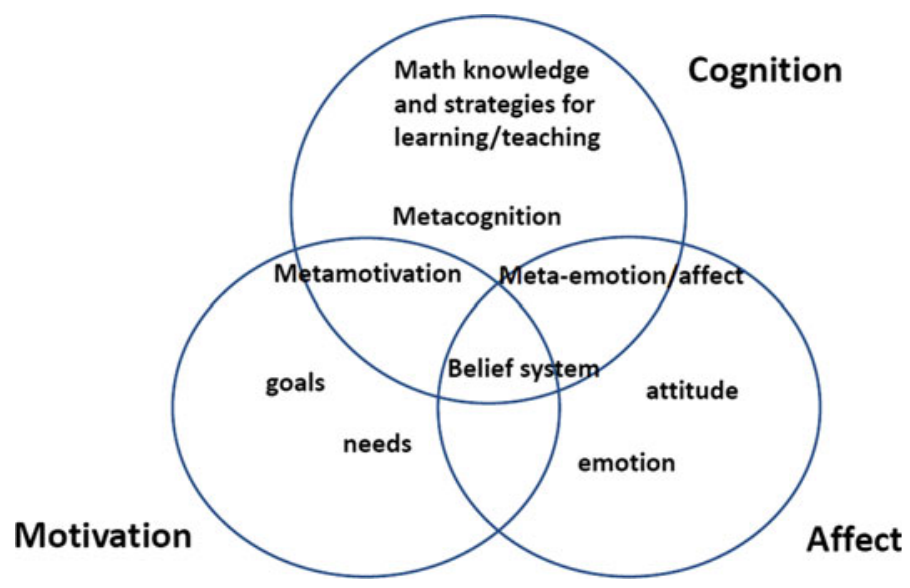

Fig. 16.1 Aspects of teachers' mathematics related affect Hannula et al. (2007)

sition): “Applications are useful to promote networked thinking". This proposition has an individual logical value for the teacher.

Goals could be understood as representing a teacher's conviction of an appropriate way of teaching (Eichler \& Erens, 2014). In contrast to beliefs, teaching goals like "I want to teach applications" or "I want my students to promote networked thinking" have no logical value. In educational psychology, goals are seen as a "representation of what it is an individual is trying to achieve in a given situation" (Wentzel, 2000). In our research we use the construct of goals as a trait, i.e. the decision making, when planning future teaching (cf. Heckhausen \& Gollwitzer, 1987). Following the definitions of beliefs and goals, beliefs connect goals on different hierarchical levels. Thus a primary goal is connected by a proposition (belief) with a subordinated goal.

There is a wide consensus that teachers' beliefs are organized in systems of beliefs (Fives \& Buehl, 2012; Green, 1971; Philipp, 2007). Three aspects that are also important for our research are described as constituting a belief system: First, beliefs are understood to have an individual grade of centrality. Thus, a teacher could hold some beliefs more strongly (central beliefs) than other beliefs (peripheral beliefs). For our purpose of describing the development of teachers' beliefs, this aspect is crucial since central beliefs seem to be more stable than peripheral beliefs (cf. Liljedahl, Oesterle, \& Bernèche, 2012). A second aspect concerns the distinction between primary and derivative beliefs (cf. Green, 1971). Finally, the third characteristic of the belief system is the existence of different clusters of beliefs that are not necessarily logically connected. Thus, beliefs could be contradictory. In our research approach, we focus particularly on a coherent mathematical topic like calculus to potentially yield a coherent system of logically connected beliefs.

In the same way like beliefs, goals could be understood to exist in different grades of centrality and could be potentially contradictory. Referring to the aspect of primary and derivative beliefs, teachers' goals could be distinguished as primary goals and 
subordinated goals emphasising the hierarchical structure of different goals (see above). Subordinated goals (e.g. teaching of applications) could be also central, but represent a technology to achieve primary goals (e.g. achieving a networked thinking).

For investigating the structure of teachers' beliefs (the first research question), we use overarching concepts of beliefs and goals represented by "world views" (Grigutsch, Raatz, \& Törner, 1998) or epistemological beliefs (Hofer \& Pintrich, 1997) about mathematics (or calculus), with reference to school mathematics or about teaching and learning mathematics. According to Grigutsch et al. (1998) we refer to four world views:

- A process-oriented view represents beliefs that mathematics is a creative activity consisting of problem solving using different and individual ways.

- An application-oriented view represents beliefs that the utility of mathematics for real world problems is the main aspect of the nature of mathematics.

- A formalist view represents beliefs that mathematics is characterised by a strongly logical and formal approach.

- A schema view represents beliefs that mathematics is a set of calculation rules and procedures to apply for routine tasks.

Although Grigutsch et al. (1998) formulated their world views referring to mathematics in general, each of the four views can be related to a certain topic like calculus. We further use a distinction of teachers' overarching goals about a learning orientation. Following Staub and Stern (2002), we refer to two different learning orientations:

- A transmission view represents beliefs that the teacher has to control students' learning and has to organise the learning process step by step.

- A constructivist view represents beliefs that the teacher must organise a learning environment in which the students create their learning process for themselves.

Finally, the research of Skott $(2009,2015)$ implies one should also take into account the "social entities" (Skott, 2009, p. 45) of different classrooms or different schools. This is especially important when considering prospective teachers after their university studies, as this constitutes the novice stage of their teacher career (Huberman, 1989). In this phase prospective teachers are confronted with the realities of mathematics teaching in the classroom that may challenge or confirm their existing beliefs. Moreover prospective teachers also become a member of school as an organisation and are influenced by the context in their socialisation (Kelchtermans \& Ballet, 2002). The socialisation process is seen as a "meaningful interaction between the beginning teacher and the school as an organisation with its different actors" (ibid., p. 106), which may influence prospective teachers' beliefs. In this paper we use the term socialisation more broadly comprising the period from own schooldays up to qualified teaching. The induction period in the transition from university to teacher training to becoming a qualified teacher needs to capture and encompass the settings of both, the specific social context of a school (Skott, 2009) and social prac- 
tices or teaching approaches promoted by teacher educators or experienced teachers (Skott, 2015).

\subsubsection{Teaching Calculus}

Teachers' beliefs and goals concerning the teaching and learning of mathematics are necessarily focused on specific mathematical objects (cf. Philipp, 2007). As outlined above, we restrict the space for these belief objects to the teaching and learning of calculus as a main topic of mathematics teaching in upper secondary schools. Regarding the teaching and learning of calculus we defined trends elsewhere (Eichler \& Erens, 2014, pp. 654-656) that consist of patterns of teachers' beliefs and goals and, thus, represent types of calculus teachers that are-except for the last type-also theoretically existent in further studies (e.g. Artigue, 1996; Oates, 2012; Robert \& Speer, 2001). We briefly explain these four trends.

- For teachers following an empirical generic trend, process-oriented goals are central whereas these teachers refuse a formalist view. Goals that potentially refer to the application-oriented view or emphasise the use of technology are subordinated to goals representing the process orientation.

- For teachers following an empirical modelling trend, application-oriented goals are central. If other goals are also central for these teachers the related goals are subordinated to goals representing the application orientation.

- For teachers following an empirical moderate New Math trend, formalist oriented goals are central. Goals that potentially refer to the application-oriented view or that emphasise the use of technology are subordinated to goals representing the process orientation.

- For teachers following an empirical schema trend, schema-oriented goals are central whereas other goals are mostly neglected.

A development of teachers' beliefs and goals in their professional socialisation could be regarded as a change between empirical trends or a change between world views. In this paper, we primarily refer to a change of the four world views that predominantly constitute the empirical trends.

In contrast to teaching goals, the topics of calculus teaching are well defined and include the concepts of function, of derivatives, of integrals or of the connection between derivatives and integrals (e.g. Tall, 2009). For this reason, the main questions for teachers in our study and even for different countries all over the world (Bressoud et al., 2016) refer to teaching goals instead of selecting specific topics. These questions that represent also parts of different trends indicated above, concern

- the extent of real applications as a main topic for calculus teaching (e.g. Blum, 2000).

- the extent of exactness when introducing concepts of calculus (e.g. Tall, 2009).

- the selection of competing approaches for concepts, e.g. the derivative. 
- the extent of using technology (e.g. Tall, 2008).

Prior research on mathematics teachers' beliefs referring to geometry, calculus and stochastics has provided evidence that teachers hold distinguishable beliefs about different mathematical objects or topics. As teachers at secondary level naturally teach all mathematical disciplines, their domain-specific beliefs vary significantly (Eichler \& Erens, 2015). Investigating (prospective) teachers' domain-specific beliefs on calculus, we refer to the trends outlined above, the mathematical world views and, finally, the aforementioned main specific questions for teaching and learning calculus when regarding the teachers in our study.

\subsection{Method}

As calculus is the core discipline of the curriculum at upper secondary level, we refer to a sample of prospective teachers qualifying for mathematics teaching in secondary schools ("Gymnasium"). To become a mathematics teacher, prospective teachers study two subjects at university followed by a second phase of a teacher education programme based at school and state institutions. In this second phase the teacher trainees attend courses taught by teacher educators (who are also teachers) consisting of subject-specific pedagogy, practical teaching content, curriculum-based lesson planning and teaching methods. These courses are complemented by part-time teaching in schools. This phase after graduating from university and before beginning their career as a qualified teacher is compulsory for prospective teachers, lasts about 18 months and includes the first intense practical experience of the prospective teachers in school. The second phase is completed with the award of a State Examination. For this graduation observed and assessed lessons and teacher training examinations are criteria. These examinations are a decisive aspect for a future career in teaching. Thus there exists a dependent relationship between educators and trainees that might affect instructional planning processes during traineeship. Therefore the perception of teacher training might be seen by prospective teachers in terms of achieving a set of given demands and views of appropriate classroom practice. These views might be ambivalent with prospective teachers' existing beliefs before or during the intervention of the teacher training programme. In this chapter we refer to a sample of ten preservice teachers (PT), who have just completed their mathematics undergraduate courses at university, and ten further teacher trainees (TT) that have participated in the subsequent teacher education programme between university and the career as a qualified teacher in school. The ten preservice teachers had just finished their final exam at university. The ten teacher trainees were in the middle of the practical phase as teacher trainee. The rationale for conducting the study with these two subgroups lies in the hypothesis, that concerning the status quo of their development as a teacher we could differ between the existence of a more retrospective consideration of appropriate teaching approaches (preservice teachers: own schooldays, university; see Richardson, 2003) and a perception of (future) teaching that is formed by 
reflection of one's own teaching practice (teacher trainees: see Oliveira \& Hannula, 2008).

In a theoretical sampling, we varied the characteristics of the 20 teachers as much as possible. Thus, the teachers were recruited from different universities and teacher training colleges from the south-western part of Germany. Since one's beliefs could be assumed to be inextricably connected to the community of (teaching) practice in a certain teacher training college or, respectively, in a certain university, this design of the data collection was crucial. In order to avoid specific correlations with teachers' further teaching subjects (e.g. physics \& mathematics), we also varied the second subject of the teachers.

In order to investigate possible belief changes, the teachers were interviewed twice with a time span of at least one year between the first and second interview. In the first interview data were collected by semi-structured in-depth interviews focusing on calculus and including different topics related to calculus, e.g. instructional content, teaching goals, reflections on the nature of calculus as a mathematical discipline and as an issue of school mathematics, the students' beliefs, and calculus textbook(s) used by the teachers. Further, we used prompts to provoke teachers' beliefs, e.g. tasks of textbooks, fictional or real statements of teachers or students concerning instructional objectives relevant to calculus. In the second interview validation of analysis of the first interview was accomplished by confronting interviewees with key statements from their first interview and eliciting either agreement or further adjusting and explanation. Further questions about self-perception concerning their development and about the influence of their teacher educators plus a set of new task-prompts were used.

For analysing the verbatim transcribed interviews, we used a qualitative coding method (Mayring, 2015) that is close to grounded theory (Glaser \& Strauss, 1967). Based on the research questions, the aim of the analysis was to determine distinguishable features of teachers' beliefs relating to the above described theoretically and empirically defined trends of calculus teaching. Coding was done by assigning text passages and statements by teachers to the four deductive categories which were described in a coding manual. In this analysing process the characteristic patterns representing the four main trends were developed and modified step by step. Additionally new categories emerged from the data material in an inductive manner such as notions of observed or experienced teaching practices or the integration of technology into classrooms specifically relating to calculus. For example, we developed codes such as 'paper-and-pencil skills' or 'technology as an instrument' to analyse teachers' beliefs regarding the advantages or disadvantages of the use of technology in mathematics classrooms. The combination of deductive and inductive categories and codes were used to analyse the whole data set of first and second interviews using a qualitative data analysis software (MaxQDA) for systematic evaluation. Data coding was conducted by at least two persons and slight differences in coding were solved by discussion and consensus. The allocation of central beliefs that we described in detail in Eichler and Erens (2015) could be attained if teachers showed this belief coherently in several episodes through the whole first interview concerning different contexts, described concrete examples, and showed reactions to interview prompts 
and tasks according to their central beliefs. By confronting participants with characteristic excerpts from their first interview and individual case summaries about central beliefs, the accuracy of interpretation of the first round of data could be validated. The hierarchy of goals, i.e. the distinction of primary and subordinated goals is similarly based on an interpretation that is validated by a coherent interpretation of different episodes of the transcripts. For illustrating a related interpretation we use the example given above in terms of a real teacher quotation: "With these applications I want to promote networked thinking." Our interpretation of this quote is that application is a means to an end and, thus, is not a primary goal, but subordinated to the goal of letting students achieve a networked thinking.

\subsection{Results}

We have organised the discussion of our results as follows: We primarily discuss the main changes in the structural elements of the teachers' belief systems that we found from the first interviews of the preservice teachers (PT) and the teacher trainees (TT) to the second interview one year later. We refer to both interviews for the aspects of application orientation, problem orientation, formalism, schema orientation and technology orientation. Finally, we discuss the main reasons for changes and also for the stability of beliefs, i.e. an orientation towards the times as a student in school, authorities of teacher trainers and final exams.

In order to understand teachers' beliefs and belief changes ingrained in personal experiences and learning trajectories it is important to reveal how (prospective) teachers approach their professional world. As "beliefs are expected to significantly influence the ways in which teachers interpret and engage with the problems of practice" (Skott, 2015, p. 19), these cannot be exhaustively described by one cluster of central beliefs or goals. As a matter of fact, many teachers in our sample show a coexistence of more than one cluster of central goals.

\subsubsection{The Application View}

The centrality of an application-oriented view is apparent in more than half of our sample. In this paper, we illustrate central beliefs by a few examples and focus on belief changes. Mrs. M, a preservice teacher (PT), explains her preference for an application-oriented introduction to the concept of the difference quotient. Her primary rationale to be application-oriented is given in this quotation, i.e.

Mrs M. (PT, 1st interview): For an introduction, I would definitely use an example with body growth or population growth. Mainly because these are questions that arouse students' interest and seem to be useful for them. 
This teacher stresses that the concept of the rate of change using realistic examples is considered to be essential together with different representations of real data to be visualized in tables, graphs and subsequently functions. Reacting positively to given prompts Mrs M. also mentions standard examples from one or two textbooks at the beginning of her teacher training. Also other teachers refer to various realityoriented examples which in their view further the illustration of function and the derivative concept. Typically one of the arguments for their rationale for application tasks constitutes the motivation and attraction of interest of their students.

In her development in the second interview Mrs M. reveals that applications have no value per se, but serve as a starting point for examining more abstract contents of calculus. However, the tasks Mrs M. used for her teaching are combined with a confirmation of an application-oriented view. Regarding her reasons for this central belief the systematic use of mathematical methods enables her to demonstrate the potential of calculus beyond pure mathematical questions.

Mrs M. (PT, 2nd interview): ...these applications should be combined with an insight into relations with the more abstract concepts - understanding the scope of such concepts and mathematical processes behind these. With exponential functions we used applications with medication degradation processes and other examples.

There are further teachers that express, in the second interview, the same structure of beliefs or rather goals as Mrs M. who considers application-oriented goals to be central but subordinated to process-oriented goals,. These teachers linked, especially in the second interviews, application orientation to comprehension of concepts going beyond the knowledge of a definition and applications are not solely used for the motivation of students. It is interesting that the aim of teaching application for further teaching goals was more clearly emphasised by these (mainly preservice) teachers.

The example of Mrs M. represents the difference between primary and subordinated goals. Since application orientation is a central goal of Mrs. M, this goal is subordinated to a primary (and central) goal, i.e. the insight into profound understanding of terminology and concepts. Realistic applications as a starting point for developing and illustrating more abstract calculus concepts constitutes a trend in mathematics education in recent years that we subsumed under the empirical generic trend (cf. Eichler \& Erens, 2015). If teachers in our sample coherently provide evidence for a central application-oriented view, this often correlates with a strong tendency to re-invent calculus concepts according to the generic principle or generic trend. For these teachers, application seems to be a means to an end to achieve process-oriented goals. In order to distinguish between the two subgroups the preservice teachers with such application-oriented beliefs show a development that application tasks are not merely a motivational tool, whereas the correlation described above remained stable for the teacher trainees.

However, we also found teachers (preservice and trainee) for whom application orientation is both a central and a primary goal.

Mr A. (TT, 1st): In my future calculus courses modelling will be very, very important. Therefore using realistic applications is a fundamental goal, e.g. modelling periodic processes; describing the problem with mathematical tools. 
This teacher trainee follows an empirical modelling trend that has been promoted in mathematics education in recent years. Realistic applications are used to learn calculus in a way that is full of relations to real-world applications. In the second interview, it was apparent that central beliefs did not change with regard to application orientation. However, the teachers' central beliefs gained partly a broader foundation and sometimes a modified rationale. For example, for $\mathrm{Mr} \mathrm{A}$. the norms in his trainee education courses become a rationale for his central belief:

Mr A. (TT, 2nd): Well, trying to establish connections between real-life problems and essential concepts of calculus has been reaffirmed in my teacher training - the larger concepts of teaching were discussed there (...) fortunately things like concept formation and application tasks have been a good match and fell on fertile ground.

Being urged to make a decision between the last two aspects mentioned in the quotation, Mr A. decided clearly in favour of a priority for applications. Thus the modelling trend from the first interview could be confirmed and a process-oriented view is subordinated.

If teachers explicitly want to integrate modelling tasks including real-data problems into their calculus teaching, their system of goals either has no further central goals or these are subordinated (e.g. Mr A.). This is the case for both the first and the second interview. Again another group of teachers can be classified for the structure of goals and even the development of these goals: those teachers who were identified to have application and process goals as a central belief cluster were asked to make a prioritising decision in the subsequent interview together with trying to elicit reasons for their choice. In all five cases teachers made their decisions for process orientation which means that application goals are still central, but subordinated. Thus in both interviews, teachers of this type understood applications as a means to achieve process orientation. The data provide insights into the development and reasoning for this belief although assumedly qualitative differences in the development of the two groups (from PT to TT vs. from TT to qualified teacher) are not visible in teachers' reasonings. To conclude, concerning the development of application-oriented goals it can be ascertained for both subgroups that in second interviews the centrality of such goals was confirmed. It is worth noting that relevant teacher trainees either show a confirmation for this central application belief with a modified rationale or see applications as a means to achieve process orientation. The latter can also be found with preservice teachers, whose rationale for this point develops beyond the motivation and attraction of student interest into calculus.

\subsubsection{Process Orientation}

For several teachers from our sample the data yields a centrality of a process-oriented view that seems also to be stable referring to the teachers' professional socialisation. We illustrate this stability based on the example of Mrs. U. (TT). She was confronted 
with four different statements. One of these statements representing a process orientation is indicated below.

Statement 1: In teaching calculus it is most important that students have studied and understood the central concepts and they can solve problems mainly by themselves.

Mrs. U. (TT) valued this statement higher than statements representing further world views and articulated her own opinion concerning her selection as follows:

Mrs U. (TT, 1st): As it is stated here, that's a bit of a danger concerning calculus, that some things are carried out just because it is done like that. The overall picture is missing then, but I have the ambition to teach calculus in encouraging students to try to connect different concepts such as differentiation and integration.

In the second interview Mrs U. confirmed her overarching central goal of a process orientation. However, in comparison to the first interview, Mrs U. considered processoriented goals in relation to goals representing other world views being subordinated to the process orientation:

Mrs U. (TT, 2nd): For me it is essential that students do not learn rules mindlessly in calculus but most importantly they should comprehend the logic and framework behind it as well as being able to solve problems by means of this framework for specific applications.

For this trainee teacher, logical thinking, connections and problem-solving issues need to be combined in order to further students' comprehension of abstract mathematical concepts such as in calculus.

In general, there are some strong indications that preservice teachers and teacher trainees expressing a process orientation as a central goal, did not change this belief neither in transition from university to teacher training nor by the influence of teacher training.

Mrs U. and other teachers show a broader reflection of their classroom practice by including different world views when they express their preference for a process orientation. Other teacher trainees showed a broader reflection of their classroom practice by taking into account possible obstacles for a process orientation. However, also these teachers maintain their process orientation as a central goal. We illustrate this finding based on the case of Mrs K. (TT). In her first interview Mrs K. mentioned that using applications in her calculus courses is equally important to a generic approach:

Mrs K. (TT, 1st): ...using these application tasks I would like to make them see the connections and the relevant thought processes.

With an increased teaching experience, however, she mentioned in the second interview that achieving a process-oriented approach in actual teaching is indeed a difficult endeavour:

Mrs K. (TT, 2nd): Well, these problem-solving strategies and investigative tasks are more strenuous for the students because they really have to think. It is not just memorizing a rule and applying formulas. Of course it is easier for 
them to do these packages of routine tasks rather than trying to discover regularities by way of examples. That's challenging - for me and for my students, but nonetheless it's more interesting.

The reflection and acknowledgement of difficulties in achieving this goal might lead to an emotional state that can be described as disillusionment. Although a teacher challenges himself to transform central teaching goals into actual classroom practice this might result in a rearrangement taking into account many contextual and social factors that overlap the central goals.

Teachers who mentioned a process orientation like Mrs K. partly indicated that heuristic and creative activities to solve problems in different ways cannot be administered to classrooms with a growing heterogeneity of students. $\mathrm{Mr} \mathrm{N}$. expressed this belief in his second interview:

Mr N. (TT, 2nd): ...whether it is really possible for them [students] to grasp the connections and problem-solving strategies very much depends on the ability of the class. If you notice that $90 \%$ percent of the group just don't get it, then one has to adjust one's teaching.

Summarizing our findings about process orientation it can be ascertained that the overall majority of teachers in our sample showed a stability in their process-oriented goals that are the core of an empirical generic trend. A further main characteristic of these teachers is that they reflect their central goal in the second interview broader than in the first interview. Due to an increased teaching experience this reflection can be found more often in second interviews of teacher trainees.

\subsubsection{Formalist View}

Only a minority of teachers can be categorized as emphasising a formalist view as a central and primary belief, although examples exist: Mr G., a teacher trainee, is one of these teachers. In the first interview Mr G. stressed the centrality of the formal deduction in calculus and emphasized e.g. sequences, convergence issues, or formal proofs.

Mr G. (TT, 1st): Well, I daresay I could do calculus at school with a more theoretical and formal approach - similar to introducing concepts in algebra and topology. Maybe for some it would make things easier, but it will probably not be possible to implement this in most courses.

In the second interview Mr G. confirmed the centrality of his formalist conceptions working as a professional teacher. However, taking into account the perspective of high school students, Mr G. acknowledges the need to simplify proofs with a certain degree of transparency as well as the need to include plausibility arguments instead of "hard" and formal mathematical proofs.

Mr G. (TT, 2nd): Looking at the proofs in calculus: I do these formally, correctly, but I have to skip the odd step, simplify or use illustrative examples for case distinctions. But without calculus, I can't do any real mathematics. 
In the second statement the emergence of a sensible compromise between his central formalist view on calculus and calculus teaching and the high challenge for his students becomes apparent. Whereas his original beliefs could be based on his mathematical socialization at the university (Ph.D. in pure mathematics), his beliefs in the second interview could be the result of the influence of colleagues, the teacher educators, and, particularly, his experiences with the students in daily classroom practice. However, there are considerable similarities with the teachers that we discussed in the former sections: The teachers' central beliefs seem to be stable. Further the teachers took into account further ways to achieve their central goals. These ways, methods or rather technologies could be understood as subordinated goals that serve as a means to an end.

The majority of teachers in our sample more or less rejected formalist goals in the first interview, as the following two quotes demonstrate:

Mrs M. (PT, 1st): These formal mathematical constructs, for example integral with lower and upper sums, is not important. [...] That's too difficult for most of them [students], very time-consuming and needs too much brain capacity which can be used more reasonably.

Mrs W. (TT, 1st): There is just no time in calculus courses for these formal developments of concepts and personally I would rather emphasize other things.

This view is confirmed in the second interview. In many cases the level of acceptance of formalism even decreased comparing first and second interviews. The reason for this decrease was explained by the high difficulty in formal abstraction especially for the weaker students. For this group of teachers, the rejection of formalist goals is predominantly restricted to issues like formal proofs. However, these teachers tend to value another notion of formalism concerning the documentation of task solutions by students. The formal correctness of task processing and its solution documentation is increasingly mentioned in the second interview.

Assumedly this could be interpreted as a quasi-logical belief in teachers' individual belief systems. The clear distinction between formal (algebraic) rigour and outcomes of student work rather hints at an alternative explanation: a necessary basic agreement in documentation needs to be accomplished in order to guarantee a common standard agreement with colleagues (comparability of results) as well as meeting the requirements set by school management authorities regarding the marking of central exams:

Mrs M. (PT, 2nd): The written solutions for tasks need to be formally correct, e.g. in class tests, just as we practiced it in lessons, and I expect students to pay attention to these, $[\ldots]$ this is especially important for them in their final exams.

These goals could be explained by reasoning that a discourse about mathematical issues is only possible if a basic framework of terminology and notation is attained. The need to acquire a common understanding about definitions and concepts in calculus focuses on a strategy of using key terms of mathematical language from a set of formal and conceptual terms. 
Mrs W. (TT, 2nd): There are certain terms and definitions that students need to know. They must know them and they need to associate the basic concept that lies behind it. If they don't know the technical term they may describe it, but I often have to remind them that these are important to know. My interest is that they can communicate about concepts and to make them know what exactly they are doing without coding things into foreign words.

Summarizing the development referring to formalist views, the comparison of data of the first and second interviews shows either a confirmation of rejecting or subordinating formalist beliefs. An increasing expression of the importance of a formal language and solution documentation can be found in the development of formalist views especially with teacher trainees working as qualified teachers at the time of second interviews.

\subsubsection{Schema View}

In their mathematical socialisation in retrospection of their own schooling in calculus many teachers in our sample make reference to a schema view in their secondary education experience in the first interview. Changing perspectives from student to teacher, the overall majority of teachers in our sample have a critical stance on a strong schema view at the first data collection and such teaching goals are at most peripheral. However there is an example of one preservice teacher who shows a schematic approach to calculus as a central goal and who sustained a calculus course in high school with characteristic elements of schematic routines and extensive emphasis on calculating derivatives:

Mr F. (PT,1st): In my high school course we practised differentiation rules without end. Perhaps this was exaggerated but in today's classes these skills are often missing (...) if you try to address application-oriented tasks the main hurdle for many students are basic differentiation rules. Therefore these skills have to be internalized.

Although excessive training of rules is seen critically, there is an implicit approval of calculation procedures required for solving more complex tasks. The identification of a schema view could coherently be established in the first interview and was confirmed in the second interview. The quotation above, however, implies that mastering calculation skills have always been and still are an essential part in his belief system and have been embedded in the changed perspective from student to teacher. Being confronted with reconsidering the importance of either process or application views in comparison with his earlier statements referring to a schema view, this teacher confirmed the priority of calculation procedures that students need to master the basics levels for all kinds of calculus tasks; especially for exam-style application-oriented tasks basic skills are indispensable in his view. For all three teachers (two trainee, one preservice) with a schema view as a central belief, such application-oriented 
(and other) goals stay clearly subordinated and peripheral in their belief system and are at most part of their system of goals.

Arguments that emerge from the data of both interviews reveal interesting developments with regard to their teacher socialisation. The majority of teachers of both subgroups judge excessive training of schematic tasks as negative although some mention experiences from their own schooling positively in first interviews. The explanation of this prior experience is simply a high success rate. A pattern can be identified with those teachers who explicitly refused emphasising a schema view in first interviews. The disaffirmation of a schema view however does not automatically imply the absence of such goals. In second interviews, due to the identification of a large heterogeneity in learner groups, these teachers propose to integrate accurately dosed schematic exercises. Preservice teachers mainly argue with particular needs of low-achieving students whereas teacher trainees additionally mention expectations of permanent colleagues who might diagnose missing skills in follow-up levels.

Mrs B. (PT, 2nd): The schematic aspect is helpful for the weaker students who don't manage to solve the complex problems anyway. Sensible exercise tasks enable these students to bring about a certain routine: they just don't get to grips with the transfer of mathematics and application.

Mr C. (PT, 2nd): ...such curve sketching tasks are always the same. Students might like that because they practise it thoroughly and have a feeling of success instead of constantly having to think about new problem-solving strategies. But basically that is boring and not reasonable.

Mr A. (TT, 2nd): Of course students need these routine tasks - the weaker students especially, (...) and of course I don't want colleagues to complain that they haven't learned enough when they take over one of my classes.

These exemplary remarks show a development in teachers' socialization process. Preservice teachers are concerned about students' mathematical success and related positive emotions in mathematics. Repeated procedural tasks are seen as a means to an end to facilitate moments of mathematical success and positively influence students' mathematical affect. Teacher trainees additionally feel the peer pressure of mathematics colleagues of their school, where they work permanently at the time of the second interview.

Not rejecting a schema approach per se, there is another development in the discussion about the pros and cons of a schema view that appeared exclusively in the data of teacher trainees. Deviating from the teachers who explicitly reject automated procedures some teacher trainees show yet another rationale when working as a qualified teacher.

Mr H. (TT, 1st): Curve sketching, yes, needs some time. But they [students] need to practice that necessarily, (...) and need to know which criteria must be checked.

Mr H. (TT, 2nd): Well, I see a certain connection between mastering the routines and problem-solving skills: if you always have to think about how the basics work you do not have the capacity to solve more complex tasks. 
These quotations from first and second interview show a development that a certain amount of procedural training is seen as necessary to be increasingly integrated for two main reasons: first basic procedures such as finding extreme points of a function are considered to be a necessary fundamental concept in a sequential hierarchy of applying mathematical knowledge to given tasks and problems in calculus. Secondly these basics are subsequently needed to achieve further superordinated goals of process and application orientation.

Apart from the developments described above, another reason for an increasing importance of schematic features in second interviews is only given by some teachers who are in transition from trainee to qualified teacher.

Mrs U. (TT, 2nd): Personally I am convinced that these [routine calculations] are less important, if not unnecessary. In the school context, however, preparing students for their exam, the significance of these tasks changes.

Even though there is a negative response to a task prompt representing a schema view, there are nuances in these teacher trainee's beliefs due to a pedagogical responsibility towards those students who are not able or less able to solve tasks going beyond memorized procedures but need at least a high success rate in standard test tasks. As both class and final examinations consist of a calculator-free part (standard tasks) and a second part where students are allowed to use graphic or symbolic calculators, the role of technology and its impact on teaching calculus will be discussed next.

\subsubsection{Role of Technology}

Regarding our sample of teachers, we found two antithetical belief systems referring to the integration of technology in upper secondary calculus courses, i.e. belief systems that we call "the old school" and "technology supporter". Teachers describing themselves as belonging to "the old school" consistently express severe doubts about technology use in helping students' mathematical learning. In contrast to "oldschool" teachers there are "technology supporters", who expressly utilise graphic and symbolic technology in order to realise a problem-oriented approach to teaching calculus. In between, our data suggest that teachers' beliefs about technology range in a continuum that extends from scepticism to reluctance up to those teachers who use the given technology in the curriculum as a means to an end.

In the same way as reported for the world views, the technology supporters and also the teachers representing the old school show a considerable stability concerning their central goals. In their development the teachers representing the old school are an example for which also negatively formulated goals show a stability or even increase. For example Mr G. expressed negatively connotated beliefs referring to the use of technology:

Mr G. (TT, 1st): One may use these calculators but it also needs time to make students understand how to use it, (...), and often things get even more com- 
plicated because they often don't know what they are actually doing mathematically. [...] I think I will do without the device as much as possible.

Mr G. (TT, 2nd): Neither in my teacher training nor in textbooks or other resources have I come across reasonable tasks where the use of a graphing calculator really makes sense. It is just translating the text task in order to operate the pocket calculator - for me that's not mathematical thinking.

In both interviews Mr G. described himself as belonging to the "old school" and does not see any benefit in using technology. The refusal of using a calculator in the first interview might still be due to challenges that novice teachers meet on a basic instrumental level. In the second interview, however, Mr G. showed an increasing rejection of such tools and stressed the view that students may be tempted to use the technological device as a universal "remedy" for problem-solving and sees more harm done than any benefit.

Teachers that tend to value technology for mathematics teaching mostly describe in the first interviews the key advantage of using technology as the possibility of visualisation of mathematical objects, e.g. functions.

Mr S. (TT, 1st): Above all, I use the calculator to visualize things, particularly when it comes to introducing new concepts. First we calculate a lot of specific values instead of abstracting the given task immediately.

Very few teachers emphasise the possibility of further benefits of using technology (Tall, 2008), e.g. checking results and relieving students from procedural investment:

Mrs E. (PT, 1st): Often my students use the calculator in order to check their results. First they think about their strategy of solving the given task and then they can reassure themselves about solutions.

As mentioned before for the development of central beliefs, the teachers for which the use of technology is a central (but subordinated) goal tend to broaden their understanding of the benefit of technology supported teaching. For example Mr S. emphasised in the second interview that he sees the benefit of technology even beyond visualisations and other reasons mentioned above.

Mr S. (TT, 2nd): ...now we use the calculator even more in terms of generating examples and then try to find conjectures. The students actually come up with hypotheses which, of course then have to be formally validated.

After completing his teacher training he wants to achieve a generic development of calculus concepts in facilitating students' conceptual learning by experimenting with mathematical objects in an inductive way.

By using technology as a means to an end, the analysis of second interviews suggests that technology increasingly paves the structural way to further support central teaching goals such as an emphasis on modelling realistic data. Actually, especially those teachers who valued high application-oriented goals or process-oriented goals also tend to value the benefit of technology highly. With respect to different stages in their professional development, there are hardly any differences between preservice 
teachers and teacher trainees. At the individual level, these teachers show similar paths of development.

Pedagogical considerations concerning technology use at secondary school are among many aspects of teachers' developmental trajectory. Methodological and instructional teaching decisions and prospective teachers' beliefs on teaching orientations will now be addressed.

\subsubsection{Teaching Orientation and Teaching Scripts}

Beliefs about learning mathematics at school may be related to the notion of personal experience and evidence-based teaching practices. Regarding the reconstruction of the teaching orientations at the point of data collection when they were in teacher training (PT, 2nd \& TT, 1st) many teachers tend to a traditional teaching script: teacher instruction followed by a method of development by questions, exercises and a joint discussion of results. In their first own teaching many teachers want to move on "safe ground" before starting experiments.

Mr H. (TT, 1st): In my lessons I would like to exercise less guidance than my own maths teacher but I am still struggling to relinquish my teacher control. But I think my students have less experience with these methods and don't feel enough responsibility that they need to produce results. I definitely have to grow into my role with more experience.

Although $\mathrm{Mr} \mathrm{H}$. and other teachers in our sample do not favour a transmission view there are numerous examples of self-reported teaching scripts which resemble a predetermined sequence of actions characterized by small steps, a method of conceptualising content by detailed teacher questions followed by single exercises. The analysis of second interviews shows a notable change. The majority of teachers report that they aim at integrating more student-centered methods of instruction with a higher degree of cognitive activation of their students. The use of exploratory tasks with a bottom-up approach either using or generating examples is often mentioned as well as the aim of a high degree of social interaction between teacher and students.

$\mathrm{Mr} \mathrm{H}$. (TT, 2nd): The more teaching experience I have the more I achieve a sound balance towards teacher-student interaction. At the beginning I wasn't able to get good [mathematical] results with these student-centered tasks, now I increasingly use these rather open teaching methods.

A changed stance about teaching calculus in contrast to a "traditional" teaching orientation seems to demonstrate that cognitive, emotional and motivational traits in his belief system moved towards a more constructivist orientation.

Specific changes that can be noticed comparing statements from both interviews regarding teaching orientation mainly concern a much higher variation of teaching concepts in implementing various formats of modern teaching methods (e.g. different formats of group work, internal differentiation or classroom management), which might result from theoretical and practical inspirations drawn from mentor teachers 
or teacher educators. However, the exact sources for these changes cannot be deduced from the data as particular trainee colleges and teacher educators may have different curricula.

Interestingly those teachers in our sample (5 out of 20) who did not see their traineeship as a benefit for their professional education and development, emphasise in their statements about their teaching orientation that quality features of good instruction in their calculus courses are a clear teacher-centered lesson structure, numerous elements of traditional teaching (e.g. teacher speaks in front of the class) and the non-suitability of calculus content for inquiry-based learning concepts. Although causal relationships between different clusters of beliefs need to be made carefully, it is worthwhile mentioning that three teachers with a rather strong transmissive teaching orientation also belong to the group of teachers who put forward a negative view towards the use of technology in calculus courses. Summarising our findings on teaching orientation it can be ascertained for one group of teachers that teaching orientation and associated lesson scripts remain very stable and are characterised by a more transmissive orientation. With a comprehensibly stronger development being noticeable in the group of teacher trainees due to their more advanced stage of professionalization, three quarters of our sample show a progression towards a higher variation of more student-centered and constructivist teaching scripts coinciding with a high adaptability of teaching methods.

\subsection{Why Do Beliefs Change or Do Not Change?}

\subsubsection{Impact and Influence of Teacher Educators or Education Program}

Since we focus in this paper on the development of beliefs, a crucial question is why these beliefs changed or did not change. Although some of the teachers refer to their own time at school or their university studies, we first focus on a potential impact on the teachers' beliefs in our study, i.e. the teacher educators in the phase of teacher traineeship. Actually, one of the aims of teacher education courses is to further develop the professional competence of prospective teachers, including teaching skills in methodical issues and the ability to process subject knowledge with regard to learning processes. This might entail to challenge existing beliefs that contradict the view of appropriate classroom practice of teacher educators. Assessed lessons and teacher training examinations are decisive criteria for the trainees' future career. Thus there exists a dependent relationship between educators and trainees that might affect instructional planning processes during traineeship.

In their training education teacher trainees work at one school and first attend lessons of experienced teachers but also teach themselves accompanied by teacher mentors. In the second year they teach classes with full responsibility. Additionally 
trainees get theoretical and practical input at education colleges in courses taught by their teacher educators.

When teacher trainees are faced with pedagogical decisions, the question is to what degree the intervention of a teacher educator effects change in trainee's beliefs. The awareness of the authority of teacher trainers can be validated in all the interviews of our sample, as the following example confirms:

Mr C. (PT, 2nd): Quite important to me is that my lessons are well-structured; and that this structure is visible especially to my teacher trainers.

We illustrate the relationship between the intervention of teacher educators and the development of teachers' beliefs with the case of Mr G. who showed a preference for formalist oriented goals (see above). Mr G. showed a reflection of teaching approaches suggested by teacher educators that seems to reshape his teaching goals:

Mr G. (TT, 1st): In conceptualizing new content I always use a task-oriented approach, which is a guideline given by our teacher trainers. In my opinion it's not bad, but I think it's too stringently guided like our trainers want it to be implemented. [...] From time to time I vary a little bit, but at the moment I must keep in mind my assessed exam lessons with my students. [...] however in doing so the teacher guidance is quite high so I sometimes think I could just demonstrate the tasks myself.

Reflecting on his first teaching experience Mr G.'s view on appropriate classroom practice is being challenged and a process of nuanced replacement takes place which is (partly) initiated by theoretical input of his teacher training course. Thus, partly the authority of a teacher trainer and partly the trainees' own reflection seem to impact on this teacher's beliefs. The implementation of a specific teaching concept is an instrument of nuanced change: On the one hand $\mathrm{Mr}$ G. expressed a strategic alignment with the teacher educator's idea on conceptualization of new content; on the other hand his reflection showed that a cognitive process of individual adaption concerning his teaching orientation is under way. The suggested "task-oriented approach" is regarded as a meaningful and appropriate inspiration on a content-related and methodological level for instructional practice. Reflecting on his instructional planning, the canonicalized nature of this approach is critisised by him as being too prescriptive. Particularly the degree of teacher guidance is associated with a rather transmissive learning orientation. His beliefs, however, are not in accordance with the teacher trainers' views, and thus his future teaching will presumably differ from the task-oriented approach, as the following quote from the second interview shows:

Mr G. (TT, 2nd): I tried out the suggestions and concepts I got there. If it works, it's ok. But drumming in particular ideas and concepts; no, that was a bit overdone. I question whether this has brought any change in my teaching.

The intervention of a teacher trainer will presumably not inaugurate any long-term change in trainee's beliefs, if there is no accordance with their reflection of their own classroom experience and also their central goals that seemed to exist before starting as teacher trainees. In second interviews teachers were explicitly asked about the influence of their teacher educators. Nearly all teachers of our sample claimed that 
their teacher educators had no or very little influence on their beliefs towards calculus teaching. The range of influence of teacher educators rather comprises pedagogical ideas and methodological suggestions in order to further teachers' instructional repertoire. About one third explicitly negate any influence of their teacher educators, such as Mrs R.:

Mrs R. (TT, 2nd): Well, some concepts and methods, which were introduced, stimulated my considerations about calculus teaching but as a result I strongly disagreed with my teacher educator, e.g. the suggestion of a formal deduction of the derivative of the sine function...that's absurd in my opinion.

These teachers disagree with their educators' conceptions for the learning and teaching of calculus and see them as supervisors and inspectors who definitely have no influence on their beliefs towards teaching calculus. Contrary to the examples described above, about two thirds of our sample acknowledged that teacher educators managed to make them develop a sense for an adaptability of teaching methods, selecting appropriate tools and resources for teaching and identifying barriers to student learning:

Mrs D. (PT, 2nd): Our instructor in my mathematics course provided us with a lot of useful material and inspirations. I used his material and suggestions not because it was expected but rather because I considered it appropriate.

Further Mrs D. reports about a planned and enacted teaching unit where she tried out inquiry-based learning methods which were analyzed with a reflective stance and suggestions for improvement. The development of an orientation to being adaptable as a teacher, to consider variations to different methods of teacher-student interaction as well as searching for alternatives to ineffective pedagogical approaches is one of the main areas of reported change or rather development mentioned by our teachers:

$\mathrm{Mr}$ T. (TT, 2nd): Influence of teacher training? Well, my lessons have hopefully become a lot more professional compared to when I started. In my courses I learned a lot about different teaching methods as well as being able to experiment with alternative methods of instruction. These I still use in my lessons now.

In determining the impact of the teacher education program, it is interesting from a cognitive and emotional perspective that young teachers' pedagogical beliefs and intended methods of instruction which have been developed or confirmed during their teacher training remain stable between the first and the second interview.

Independent of the level of acceptance towards the teaching conceptions of teacher trainers, our data suggests that neither teacher educators nor education courses are agents of belief change concerning mathematical world views or trends of an intended calculus teaching. As one teacher put it metaphorically: "you can't teach against your personal convictions-that's like wearing a wrong coat and it doesn't fit". This metaphor, of course, refers to central beliefs. In contrast, nearly every teacher shows slight changes in indicating new or modified subordinated or rather peripheral beliefs referring to the teaching of calculus. To conclude, preservice and trainee teachers' deep-seated beliefs about calculus are not affected by teacher educators 
whereas changes are noticeable in their teaching orientation. To what extent these changes occur does not only depend on the acceptance of teacher educators as a benefit for teachers' professional development but additionally on whether teachers follow a transmissive or more constructivist learning orientation (see 16.4.6. teaching orientations). Further positive and negative experiences in teacher training courses might affect possible changes. Concerning the point of possible changes (rather in the first or second year of teacher training, i.e. 2nd interview of PT or TT) our data does not show any discernible contrasts.

\subsubsection{Influence of Final Exams}

Apart from the intervention of teacher training, another important factor that interferes with teachers' beliefs during teacher training is students' final examinations as an external authority. Assumptions that mathematics teaching is too much focused on task requirements of central examinations have been confirmed and are logically named teaching-to-the-test-effects (Maag Merki, 2011). The degree of concern might still be less prevalent as preservice and trainee teachers usually have little need to deal with central exams in their first practice experiences. It is an expected and established result that preservice teachers are mainly preoccupied with substantial issues of their lesson planning (cf. Oliveira \& Hannula, 2008). Therefore this external authority and its possible effect on intended calculus teaching with a focus on schematic and exam-style training is touched—if at all—only superficially in first interviews and slightly rises in second interviews. The degree of examination concerns increases more significantly when comparing both interviews of teacher trainees. In particular teacher trainees show an expanding orientation towards selecting exam-style tasks, as requirements of examination tasks are analyzed and serve as a benchmark. As mentioned in the section about a schema view, schematic routines are assigned a greater role in some teachers' belief system but remain subordinated to other central goals. To the same end and with similar reasons, some teachers' views on formalist and application goals play a more crucial role with regard to trends of application tasks and formal documentation in examinations.

\subsubsection{Influence of Prior Beliefs and Social Context}

Taking into account what is known about the development of preservice teachers, research on preservice teacher beliefs has produced evidence that prior beliefs serve as a filter for their professional learning in teacher education (Kagan, 1992; Richardson, 2003). Prior beliefs that originate from own experiences learning mathematics at school include pedagogical beliefs about goals and instructional preferences referring to specific contents of mathematics teaching. As teachers were asked explicitly in the first interview about their own high-school background concerning calculus it 
is possible to elicit characteristic lines of argumentation, e.g. memorized procedures such as intensely practiced derivation rules as well as curve sketching were partly attributed positively, either because of a personal high success rate or as they were seen as a necessary prerequisite for mathematics courses at university. However, beliefs that calculus is a collection of rules and procedures are firmly rejected by most teachers. As shown above assessment requirements, on the other hand, do have an influence on teachers' beliefs as the significance of memorized procedures, which have to be applied to corresponding examination tasks, is reaffirmed but remains subordinated.

Possible origins of central beliefs could be identified with regard to milestones of teachers' mathematical socialisation. In the case of Mr G., his mathematical career included a Ph.D. in pure mathematics which might explain his central formalist views. In his first interview evidence can be found that there exists a discontinuity between working on mathematical research and teaching calculus to high school students. His beliefs in the second interview change as a result of the indirect influence of teacher educators and, particularly, his experiences with the students in classroom practice. Referring to the discontinuity of university level of formality to the school level, some teachers' beliefs change. There is a decrease of formalist goals related to the moderate New Math trend and associated therewith, especially noticeable with teacher trainees, a rising intention of a correct and meaningful usage of mathematical terminology and language in classroom discourse.

Starting into their teaching career, novice preservice teachers and teacher trainees quickly notice a potential and actual gap between their own beliefs, theoretical aspects on teaching issues from their university or education courses and actual classroom experiences. According to recent research literature there exist different kinds of these gaps, one of these being the transition point from university into teaching (Gueudet et al., 2016). Reflecting on possible mismatches our teachers show that a cognitive process of individual adaption concerning these issues is under way. Reflection as a crucial variable of teachers' development of beliefs is also reported by Decker, Kunter, and Voss (2015) or Skott (2015).

Further belief changes can be found in second interviews of preservice teachers when they reflect on their collaboration with experienced mathematics teachers at their school. Meeting expectations of a school-based curriculum for secondary calculus classes constitutes a reason for increasing views of application orientation according to the modelling trend, as exam-style tasks also include problems with application contexts. Both groups of teachers in our sample thus show a growing sense of the institutional setting and social norms, in particular teacher trainees in second interviews are aware of both, peer support and pressure. Their beliefs and goals relate dynamically to the given social context.

However, there are considerable similarities with the teachers that we discussed in the former sections: The teachers' central beliefs seem to be stable whereas subordinate beliefs are modified or change depending on teachers' perceptions of their social and professional context and, correspondingly, the opportunities and limits of potential change. 


\subsection{Discussion and Conclusion}

As illustrated by examples of teachers in our sample the professional socialisation between the end of university studies and their start as qualified teachers yields both, a stability of central and primary beliefs and goals and a change and rearrangement of subordinated goals and peripheral beliefs.

Mrs K. (TT, 2nd): I think that these core beliefs are something one sticks to - that is just a teaching conviction that hardly changes - at least with me. Nevertheless - especially for me as a young teacher at the beginning of my career, I will hopefully develop my lessons further and further. But the really big concepts for my teaching will not change dramatically.

Indeed our sample of preservice and trainee teachers confirms this statement. Those beliefs which were identified to be central in the first interview were confirmed by the teachers in the second interview as concerns the above mentioned views of application, schema, formalist and process orientation. Slight but minor shifts in the hierarchical structure occurred for the whole sample but we found a remarkable stability concerning these beliefs.

On the one hand, our research does not agree with the findings of Dann et al. (1981) or Huberman (1989) whose research implied a considerable change of beliefs as a result of the first practical experiences. This is especially the case when central beliefs are regarded. However, our study could not yield a deeper insight whether slight changes of subordinated beliefs or the appearance of peripheral beliefs are a starting point for further changes. Further, our results agree with the statement of Liljedahl et al. (2012) concerning the stability of central beliefs. Referring also to Liljedahl the stability of central beliefs is not a tautology in our study since we defined central beliefs as coherently expressed beliefs in different situations in our interviews (see above). Concerning slight changes in the development of central beliefs, the results for both subgroups show that teachers give more profound reasons for their central beliefs and goals and reveal pragmatic yet sophisticated patterns of argumentation (e.g. central formalist and schema view). Due to teachers' ongoing professional development in their traineeship and increasing teaching experience, it is not surprising that the spectrum of arguments by trainee teachers is qualitatively broader than that of preservice teachers. Regarding peripheral beliefs changes, such as shifts in selecting suitable training tasks (schema), setting requirements for correct mathematical terminology (formalism) and variation of teaching methods, one could simply argue that these happen as a result of practical teaching experience.

However, when looking at possible points of rupture in the education of future teachers in more detail, it is possible to identify some mechanisms and reasons for belief changes. Regarding our sample of teachers, it seems possible to partly ascertain two overarching factors of potential belief changes which are intertwined with each other, namely authority and reflection.

The first factor involves different issues like the (anonymous) teacher of a prospective teacher's own schooldays. Interestingly, our research provides hardly any indication for a transfer of beliefs and concepts of teachers' own schooldays that was 
partly suggested in the literature (cf. Kaasila et al., 2006). By contrast, our teachers seem to hold contradictory beliefs to their schooldays in terms of rejecting a pure schema view. Other authorities for our teachers are their teacher trainer or mathematical experiences in university studies. Actually, our teachers seldom refer to university studies but mainly refer to teacher trainers. However, the teacher trainers seem to have at most a slight impact on the teachers' beliefs. If prospective teachers' teaching orientation is in accordance with conceptions conveyed by teacher trainers, these are adopted. Our results however show that teacher trainers are no agents of belief change concerning central beliefs about calculus teaching. Finally, a more impacting authority are centralized exams which is in line with the findings of Maag Merki (2011).

The factor of reflection is based on a (self-referred) reflection including the experience as student in school or university, but in particular the reflection of teaching and learning in the teachers' first practical experience. Reflection also includes considering the growing heterogeneity of students as well as an individual need to establish a coherence of content beliefs towards calculus and respectively a further adaptability of instructional teaching conceptions. With hardly any practical experience in teaching before starting teacher traineeship, this reflection seems to be a scaffolding process gaining importance particularly in the second half of traineeship, as the findings from our data suggest. The crucial influence of reflection for the teachers in our sample is in accordance with the findings of several researchers: For example, also Cooney, Shealy, and Arvold (1998) reported that reflection plays a crucial role in teacher development. Similar statements have been given more recently on the basis of research reviews or empirical studies by Fives and Hill (2015) or Decker et al. (2015).

With the insights gained from this investigation, one might aim at more longitudinal research for extended periods. Following teachers through their teacher education and their first year of teaching is a start to understand how teachers' beliefs develop throughout their career (cf. Levin, 2015). As mentioned before, an interesting question is if the slight changes in the belief systems of our teachers are a temporary phenomenon or the starting point for further development and, potentially, also a change of central beliefs. Since our research also yielded results of experienced teachers who sometimes prefer more intensely formalist goals (see Eichler \& Erens, 2014), one could hypothesize that the slight development of teachers' beliefs in the direction of formalist oriented goals could result in a stronger development in the first years as a qualified teacher. However, to gain insight in this development, a stronger focus on a long-term development is necessary (cf. Levin, 2015) to investigate whether and how beliefs develop considering cognitive and motivational aspects of teachers' mathematics-related affect. 


\section{References}

Artigue, M. (1996). Learning and teaching elementary analysis. In C. Alsina, J. M. Alvarez, M. Niss, A. Pérez, L. Rico, \& A. Sfard (Eds.), 8th International Congress on Mathematics Education-Selected Lectures (pp. 15-30). Sevilla: S.A.E.M. Thalès.

Bernack-Schüler, C., Leuders, T., \& Holzäpfel, L. (2015). Understanding pre-service teachers' belief change during a problem solving course. In C. Bernack-Schüler, R. Erens, T. Leuders, \& A. Eichler (Eds.), Views and beliefs in mathematics education (pp. 81-93). Wiesbaden, Germany: Springer.

Blum, W. (2000). Perspektiven für den Analysisunterricht. Der Mathematikunterricht, 46(4/5), $5-17$.

Bressoud, D., Ghedamsi, I., Martinez-Luaces, V., \& Törner, G. (2016). Teaching and learning of calculus. In G. Kaiser (Ed.), Teaching and learning of calculus. ICME-13 Topical Surveys. Cham, Switzerland: Springer.

Clarke, D., \& Hollingsworth, H. (2002). Elaborating a model of teacher professional growth. Teaching and Teacher Education, 18, 947-967.

Cooney, T. J., Shealy, B. E., \& Arvold, B. (1998). Conceptualizing belief structures of preservice secondary mathematics teachers. Journal for Research in Mathematics Education, 29(3), 306-333.

Dann, H. D., Müller-Fohrbrodt, G., \& Cloetta, B. (1981). Sozialisation junger Lehrer im Beruf: "Praxisschock" drei Jahre später. Zeitschrift für Entwicklungspsychologie und pädagogische Psychologie.

Decker, A. T., Kunter, M., \& Voss, T. (2015). The relationship between quality of discourse during teacher induction classes and beginning teachers' beliefs. European Journal of Psychology of Education, 30(1), 41-61.

Eichler, A., \& Erens, R. (2014). Teachers' beliefs towards teaching calculus. ZDM-The International Journal on Mathematics Education, 46(4), 647-659.

Eichler, A., \& Erens, R. (2015). Domain-specific belief systems of secondary mathematics teachers. In B. Pepin \& B. Roesken-Winter (Eds.), From beliefs to dynamic affect systems in mathematics education (pp. 179-200). Dordrecht, The Netherlands: Springer.

Fives, H., \& Buehl, M. M. (2012). Spring cleaning for the "messy" construct of teachers beliefs: What are they? Which have been examined? What can they tell us? In K. R. Harris, S. Graham, \& T. Urdan (Eds.), APA Educational Psychology Handbook (Vol. 2, pp. 471-499). Washington, DC: APA.

Fives, H., \& Hill, M. G. (Eds.). (2015). International handbook of research on teachers' beliefs. New York, NY: Taylor and Francis, Routledge.

Franke, M. L., Kazemi, E., \& Battey, D. (2007). Understanding teaching and classroom practice in mathematics. F. K. Lester (Ed.), Second handbook of research on mathematics teaching and learning (pp. 225-256). Charlotte, NC: Information Age.

Glaser, B., \& Strauss, A. (1967). The dicovery of grounded theory. Chicago, IL: Aldine.

Green, T. (1971). The activities of teaching. New York, NY: McGraw-Hill.

Grigutsch, S., Raatz, U., \& Törner, G. (1998). Einstellungen gegenüber Mathematik bei Mathematiklehrern. Journal für Mathematikdidaktik, 19(1), 3-45.

Gueudet, G., Bosch, M., Disessa, A., Kwon, O. N., \& Verschaffel, L. (2016). Transitions in mathematics education. In G. Kaiser (Ed.), Transitions in mathematics education. ICME-13 Topical Surveys. Cham, Switzerland: Springer.

Gutiérrez, A., Leder, G. C., \& Boero, P. (Eds.). (2016). The second handbook of research on the psychology of mathematics education: The journey continues. New York, NY: Springer.

Hannula, M. S. (2012). Exploring new dimensions of mathematics-related affect: Embodied and social theories. Research in Mathematics Education, 14(2), 137-161.

Hannula, M. S., Op 't Eynde, P., Schlöglmann, W., \& Wedege, T. (2007). Affect and mathematical thinking. In D. Pitta-Pantazi \& G. Philippou (Eds.), European Research in Mathematics Educa- 
tion V, Proceedings of the Fifth Congress of the European Society for Research in Mathematics Education (pp. 202-208). Cyprus: Department of Education, Larnaca, University of Cyprus.

Heckhausen, H., \& Gollwitzer, P. M. (1987). Thought contents and cognitive functioning in motivational versus volitional states of mind. Motivation and Emotion, 11(2), 101-120.

Hofer, B. K., \& Pintrich, P. R. (1997). The development of epistemological theories: Beliefs about knowledge and knowing in their relation to learning. Review of Educational Research, 67, 88-140.

Huberman, M. (1989). The professional life cycle of teachers. Teachers College Record, 91(1), $31-57$.

Kaasila, R., Hannula, M. S., Laine, A., \& Pehkonen, E. (2006). Facilitators for change of elementary teacher student's view of mathematics. In J. Novotná, H. Moraová, M. Krátká, \& N. Stehlíková (Eds.), Proceedings of the 30th Conference of the International Group for the Psychology of Mathematics Education (Vol. 3, pp. 385-392). Prague, Czech Republic: Charles University.

Kagan, D. M. (1992). Implication of research on teachers' belief. Educational Psychologist 27(1), 65-90.

Kelchtermans, G., \& Ballet, K. (2002). The micropolitics of teacher induction. A narrativebiographical study on teacher socialisation. Teaching and Teacher Education, 18(1), 105-120.

Levin, B. (2015). The development of teachers' beliefs. In H. Fives \& M. G. Hill (Eds.), International handbook of research on teachers' beliefs (pp. 48-65). New York, NY: Taylor and Francis, Routledge.

Liljedahl, P. (2010). Noticing rapid and profound teacher change. Journal of Mathematics Teacher Education, 13(5), 411-423.

Liljedahl, P., Oesterle, S., \& Bernèche, C. (2012). Stability of beliefs in mathematics education: A critical analysis. Nordic Studies in Mathematics Education, 17(3-4), 101-118.

Maag Merki, K. (2011). The introduction of state-wide exit examinations: Empirical effects on math and English teaching in German academically oriented secondary schools. In M. A. Pereyra, H.G. Kotthoff, \& R. Cowen (Eds.), PISA under examination: Changing knowledge, changing tests and changing schools (pp. 125-142). Rotterdam, The Netherlands: Sense.

Mayring, P. (2015). Qualitative content analysis: Theoretical background and procedures. In A. Bikner-Ahsbahs, C. Knipping, \& N. C. Presmeg (Eds.), Approaches to qualitative research in mathematics education (pp. 365-380). Dordrecht, The Netherlands: Springer.

Oates, G. (2012). Applications and implications of recent research for teaching calculus: A report from the 2011 delta conference on undergraduate mathematics teaching and learning. In Proceedings of the 12th International Congress on Mathematical Education, 8-15 July, 2012, COEX, Seoul, Korea. Seoul: International Congress on Mathematical Education ICME-12.

Oliveira, H., \& Hannula, M. S. (2008). Individual prospective mathematics teachers: Studies on their professional growth. In K. Krainer \& T. Wood (Eds.), Participants in mathematics teacher education (pp. 13-24). Rotterdam, The Netherlands: Sense.

Pajares, F. M. (1992). Teachers' beliefs and educational research: Cleaning up a messy construct. Review of Educational Research, 62(3), 307-332.

Philipp, R. A. (2007). Mathematics teachers' beliefs and affect. In F. K. Lester (Ed.), Second handbook of research on mathematics teaching and learning (pp. 257-315). Charlotte, NC: Information Age.

Richardson, V. (2003). Preservice teachers' beliefs. In J. Raths \& A. McAninch (Eds.), Teacher beliefs and classroom performance: The impact of teacher education (Vol. 6, pp. 1-22). Greenwich, CT: Information Age.

Robert, A., \& Speer, A. (2001). Research on the teaching and learning of calculus/elementary analysis. In D. Holten (Ed.), The teaching and learning of mathematics at university level (pp. 283-299). Berlin, Germany: Springer.

Schraw, G., \& Sinatra, G. M. (2004). Epistemological development and its impact on cognition in academic domains. Contemporary Educational Psychology, 29, 95-102. https://doi.org/10.1016/ j.cedpsych.2004.01.005.

Skott, J. (2009). Contextualising the notion of 'belief enactment'. Journal of Mathematics Teacher Education, 12, 27-46. 
Skott, J. (2015). The promises, problems, and prospects of research on teachers' beliefs. In H. Fives \& M. G. Hill (Eds.), International handbook of research on teachers' beliefs (pp. 13-30). New York, NY: Taylor and Francis, Routledge.

Speer, N. M. (2005). Issues of methods and theory on the study of mathematics' teachers' professed and attributed beliefs. Educational Studies in Mathematics, 58, 361-391. https://doi.org/10.1007/ s10649-005-2745-0.

Staub, F., \& Stern, E. (2002). The nature of teacher's pedagogical content beliefs matters for students' achievement gains: Quasi-experimental evidence from elementary mathematics. Journal of Educational Psychology, 94(2), 344-355.

Tall, D. (2008). Technology and calculus. In M. K. Heid \& G. W. Blume (Eds.), Research on technology and the teaching and learning of mathematics: Synthesis, cases and perspectives. Vol. 1: Research synthesis (pp. 207-258). Charlotte, NC: Information Age.

Tall, D. (2009). Dynamic mathematics and the blending of knowledge structures in the calculus. ZDM - The International Journal on Mathematics Education, 41(4), 481-492.

Wentzel, K. R. (2000). What is it that I'm trying to achieve? Classroom goals from a content perspective. Contemporary Educational Psychology, 25(1), 105-115.

Open Access This chapter is licensed under the terms of the Creative Commons Attribution 4.0 International License (http://creativecommons.org/licenses/by/4.0/), which permits use, sharing, adaptation, distribution and reproduction in any medium or format, as long as you give appropriate credit to the original author(s) and the source, provide a link to the Creative Commons license and indicate if changes were made.

The images or other third party material in this chapter are included in the chapter's Creative Commons license, unless indicated otherwise in a credit line to the material. If material is not included in the chapter's Creative Commons license and your intended use is not permitted by statutory regulation or exceeds the permitted use, you will need to obtain permission directly from the copyright holder.

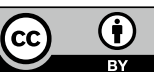

